\title{
Ultrasound imaging and guidance in the management of post-injection sciatic neuropathy: Love, loss and space
}

\author{
Vincenzo Ricci ${ }^{1}$ D, Levent Özçakar² (D) \\ ${ }^{1}$ IRCCS Rizzoli Orthopaedic Institute, Department of Biomedical and Neuromotor Science, Physical and Rehabilitation Medicine Unit, Bologna, Italy \\ ${ }^{2}$ Department of Physical Medicine and Rehabilitation, Hacettepe University Medical School, Ankara, Turkey
}

Received: January 08, 2020 Accepted: March 17, 2020 Published online: May 18, 2020

To the Editor,

We have taken interest in the article by Şencan et al. 2019;65:406-10 which has been recently published in your journal. ${ }^{[1]}$ While we congratulate the authors for their great effort in calling attention to the value of imaging-guided procedures in the management of post-injection sciatic neuropathy, we would like to put emphasis on particular issues.

'For love, you never look where you lost it' and post-injection sciatic neuropathy is simply not love. As such, we, first and foremost, disagree with the authors in their look concerning the diagnostic algorithm. Herein, although we disagree with them, they might actually agree with us in the sense that imaging should have initially been done for the sciatic nerve and the nearby soft tissues. Yet, they have already/supportingly observed thickening of the nerve in one of their patients. So, why not putting an ultrasound (US) probe on the sciatic nerve and scan it throughout? This patient - and physician-friendly technique with an appropriate/prompt use - would have definitely changed the overall scenario: i.e., not only for the clinical decision making, but also for better interventional targeting (Figure 1). ${ }^{[2]}$ Needless to say, there is simply no better imaging method for these patients, if sono-palpation or sono-Tinel yields consistent findings during dynamic and interactive imaging. To this end, US scanning is already referred as an examination method, not imaging anymore. ${ }^{[3,4]}$
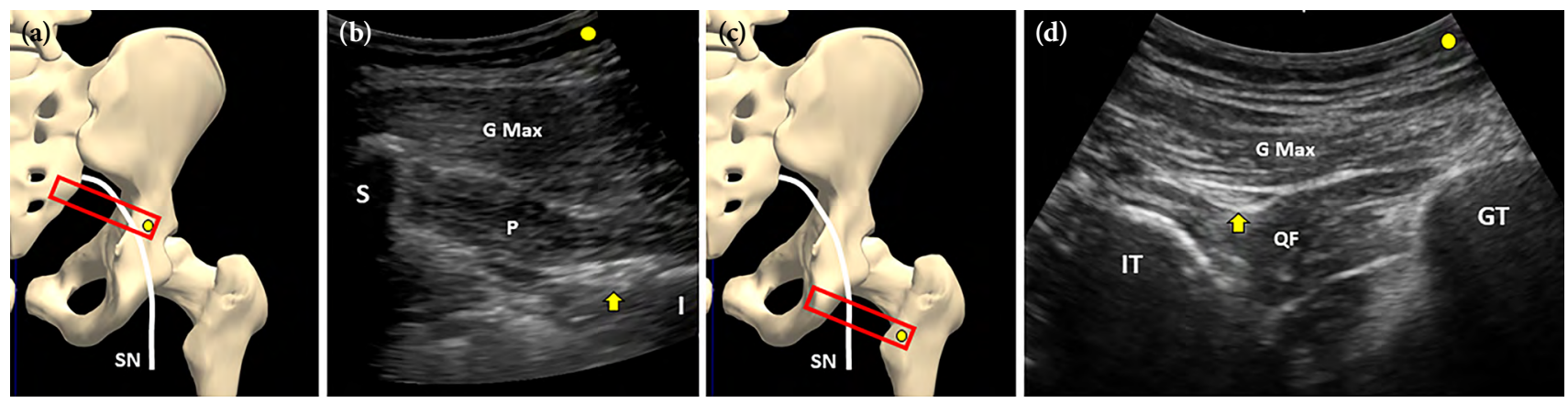

Figure 1. Sonotracking of the Sciatic Nerve in the Gluteal Region. Positioning the probe (red rectangle) in an oblique transverse plane over the gluteal region, it is possible to visualize the sciatic nerve (yellow arrow) in short -axis, from a proximal (a, b) to distal (c, d) direction. The deep location under the piriformis muscle $(P)$ immediately out of the greater sciatic foramen $(\mathbf{a}, \mathbf{b})$ and the superficial location over the quadratus femoris muscle (QF) in the ischio-femoral space (c, $\mathbf{d}$ ) can be used as basic acoustic windows for prompt sonographic navigation.

SN: Sciatic nerve; G Max: Gluteus maximus muscle; S: Sacrum; P: Piriformis muscle; I: Ileum; IT: Ischial tuberosity; QF: Quadratus femoris muscle; GT: Greater trochanter.

Corresponding author: Vincenzo Ricci, MD. IRCCS Rizzoli Orthopaedic Institute, Department of Biomedical and Neuromotor Science, Physical and Rehabilitation Medicine Unit, 40125 Bologna, Italy. e-mail: vincenzo.ricci58@gmail.com 
Likewise, before we attribute certain peripheral nerve pathologies to the dark side of neuropathic pain, we strongly imply that sonographic evaluation of the nerves coupled with clinical and electrodiagnostic assessment is invaluable. In the three reported patients, US could have clearly identified myriad pathological findings pertaining to the sciatic nerve itself (e.g. focal thickening due to intraneural edema/ intraneural fibrosis, positive power Doppler due to local hyperemia) ${ }^{[5]}$ or to the perineural soft tissues (e.g. fluid collection around the perineurium, edema/ hematoma/fibrosis of the nearby muscles causing secondary compression of the nerve) ${ }^{[6]}$ Undoubtedly, each and every particular condition would have prompted the authors toward several alternatives in the therapeutic algorithm: i.e., before transsacral blockage. Of an additional note, US imaging of the sciatic is significantly contributory as regards the medicolegal discussions for these patients. In our clinical practice, pertinent consultations from the Forensic Medicine department (for sciatic nerve US) is commonplace.

Concerning the interventions applied to the three patients, we again believe that the authors would agree with us on the insufficiency of S1-S3 nerve blocks for a neuropathy (if any), where the lumbar roots are more likely to be involved. Yet, they have already touched upon this issue in their report. Further, the lack of motor functional recovery in all the three patients does also augment our argument. In our experience, we have several cases improved with sciatic injections, whereby prompt targeting (i.e., deciphering the exact pathology, choosing the precise access and correct injectate) is applied upon US findings. Again with all these available discussions, optimal reassurance is readily given to the patients and, for sure, they accept a simple/single needle back in their body without any anxiety, instead of several needles all of which are only guided with bony landmarks ironically/generally for soft tissue injections.

Last but not least, aside from its several superiorities, US-guided spinal interventions have never been shown to be inferior to either computed tomography or fluoroscopy in the literature. ${ }^{[7,8]}$ Accordingly, if sacral injections are really needed in these patients, they can be easily done under US guidance, as well. 'Coming back to love': US imaging and guidance (with an equal emphasis) are paramount for interventional procedures where you simply avoid 'unnecessary love messages sent to space': i.e., an incorrect diagnosis with eventual inappropriate and/or unreasonable targeting. ${ }^{[9]}$

\section{Declaration of conflicting interests}

The authors declared no conflicts of interest with respect to the authorship and/or publication of this article.

\section{Funding}

The authors received no financial support for the research and/or authorship of this article.

\section{REFERENCES}

1. Şencan S, Cüce İ, Gündüz OH. Use of fluoroscopic-guided transsacral block for the treatment of iatrogenic postinjection sciatic neuropathy: Report of three cases. Turk J Phys Med Rehab 2019;65:406-10.

2. Hung CY, Hsiao MY, Özçakar L, Chang KV, Wu CH, Wang TG, et al. Sonographic Tracking of the Lower Limb Peripheral Nerves: A Pictorial Essay and Video Demonstration. Am J Phys Med Rehabil 2016;95:698-708.

3. Ricci V, Özçakar L. From "Ultrasound Imaging" to "Ultrasound Examination": A Needful Upgrade in Musculoskeletal Medicine. Pain Med 2019. [Epub ahead of print]

4. Ricci V, Özçakar L. Ultrasonographic eXamination: The 'X-factor' in Physiatry. Am J Phys Med Rehabil 2019. [Epub ahead of print]

5. Kara M, Özçakar L, Tiftik T, Kaymak B, Özel S, Akkuş $S$, et al. Sonographic evaluation of sciatic nerves in patients with unilateral sciatica. Arch Phys Med Rehabil 2012;93:1598-602.

6. Kara M, Özçakar L, Tan E, Akıncı A. Ultrasonographic imaging of the sciatic nerve in a patient with knife injury. Muscle Nerve 2015;51:303-4.

7. Loizides A, Gruber H, Peer S, Galiano K, Bale R, Obernauer J. Ultrasound guided versus CT-controlled pararadicular injections in the lumbar spine: a prospective randomized clinical trial. AJNR Am J Neuroradiol 2013;34:466-70.

8. Loizides A, Gruber H, Peer S, Brenner E, Galiano K, Obernauer J. A new simplified sonographic approach for pararadicular injections in the lumbar spine: a CT-controlled cadaver study. AJNR Am J Neuroradiol 2011;32:828-31.

9. Özçakar L. Ultrasound Imaging \& Guidance for Musculoskeletal Interventions in Physical and Rehabilitation Medicine. Milan: Edi.Ermes; 2019. 